\title{
Transporte Fluvial e Aéreo na Amazônia Legal: um estudo de caso no Município de Eirunepé - Amazonas
}

\author{
River and Air Transportation in the Legal Amazon: a study of case in the Municipality \\ of Eirunepé - Amazonas
}
Transporte Fluvial y Aéreo en la Amazonia Legal: un estudio de caso en el Municipio de Eirunepé - Amazonas

\author{
Klintia Costa Lacerda ${ }^{1}$
}

Nágila dos Santos Situba²

\begin{abstract}
RESUMO: No espaço geográfico a globalização se apresenta com novas características e novas funcionalidades, induzindo mudanças no território e no lugar. Neste sentido, tendo como ponto de partida o uso da técnica e o fluxo do dinheiro, buscou-se neste estudo compreender os fluxos aéreos e fluviais no Município de Eirunepé, localizado a sudoeste do Estado do Amazonas. Nesta região da Amazônia legal o transporte aéreo e o fluvial permitem a conexão de centros urbanos longínquos com a capital, além disso, permitem o fluxo de pessoas e mercadorias. Para tanto, a metodologia utilizada nesta pesquisa foi estudo bibliográfico, coleta de dados primários e secundários, observação direta e indireta, pesquisa de campo e entrevistas semiestruturadas. Em suma, os resultados obtidos mostraram que a população eirunepeense utiliza com frequência os dois modos de transporte; os preços das passagens aéreas são elevados devido a não concorrência; a MAP Linhas Aéreas e a Amazonaves são as únicas empresas que oferecem serviços aéreos nessa microrregião; devido à inexistência de rodovias e o difícil acesso por vias fluvial na vazante a única alternativa de deslocamento é aérea.
\end{abstract}

PALAVRAS-CHAVE: Transporte. Amazônia Legal. Fluxos.

ABSTRACT: In the geographical space, globalization presents itself with new features and new functionalities, inducing changes in territory and place. In this sense, taking as its starting point the use of the technique and the flow of money, this study aimed to understand the air and river flows in the municipality of Eirunepé, located southwest of the state of Amazonas. In this region of the legal Amazon, air and river transportation allows the connection of distant urban centers with the capital, besides allowing the flow of people and goods. Therefore, the methodology used in this research was a bibliographic study, primary and secondary data collection, direct and indirect observation, field research and semi-structured interviews. In sum, the results obtained showed that the Eirunepé population often uses both modes of transport; airfares are high due to non-competition; MAP airlines and Amazonaves

\footnotetext{
1 Universidade do Estado do Amazonas. Av. General Rodrigo Octavio Jordão Ramos, 1200 - Coroado I, Manaus - AM, 69067-005. acrenet.ern@gmail.com.

2 Universidade Federal Fluminense - UFF. Instituto de Geociências. Rua Gal. Milton Tavares, s/n - Boa Viagem Niterói - RJ - CEP 24210-346. nagilasituba@hotmail.com.
} 
arlines are the only companies offering air services in this microregion; Due to the lack of highways and the difficult access by waterways in the ebb, the only alternative of displacement is aerial.

KEYWORDS: Transportation. Legal Amazon. Flows.

RESUMEN: En el espacio geográfico, la globalización se presenta con nuevas características y nuevas funcionalidades, induciendo cambios en el territorio y en el lugar. En este sentido, teniendo como punto partida el uso de la técnica y el flujo del dinero, se buscó mediante este estudio comprender los flujos aéreos y fluviales en el municipio de Eirunepé, localizado al suroeste del Estado de Amazonas. En esa región de la Amazonia Legal, el transporte aéreo y el fluvial permiten la conexión de centros urbanos distantes con la capital, más allá de eso, permiten el flujo de personas y mercaderías. Por tanto la metodología utilizada en esta investigación fue estudio bibliográfico, recolección de datos directa e indirecta, investigación de campo y aplicación de entrevistas semiestructuradas. En resumen, los resultados obtenido muestran que, la población eirunepeense utiliza con frecuencia los dos modos de transporte; los precios de los pasajes aéreos son elevados debido a la poca concurrencia; la MAP Líneas Aéreas y la Amazonaves son las únicas empresas que ofrecen servicios aéreos en esa microrregión; debido a la inexistencia de carreteras y el difícil acceso por vías fluviales en la época de reflujo, la única alternativa de desplazamiento es aérea.

PALABRAS-CLAVE: Transporte. Amazonia Legal. Flujos.

\section{INTRODUÇÃO}

A Amazônia Legal, sendo uma vasta região de floresta, apresenta núcleos urbanos situados ao longo de seu rio principal. Nesse sentido, o Amazonas se apresenta como o maior estado em extensão territorial da Região Norte e sua hidrografia permite a fluidez geográfica entre as cidades. Por outro lado, o tempo e o espaço determinam a vida nessa região que, "[...] apesar do tamanho, é no lugar que está a dimensão da vida, o que não é suficiente para atenuar o esquecimento" (OLIVEIRA, 2000, p. 23).

Todavia, esse espaço socialmente produzido pelo homem e para o homem na Amazônia é resultado de relações históricas e práticas sociais. Por isso, ao falar de Amazônia é preciso levar em consideração suas especificidades e singularidades, buscando entendê-la em sua totalidade.

Aqui, o ir e vir estão relacionados ao rio, este sendo a rede de conexão entre os centros urbanos. Sendo assim, será por meio do transporte fluvial e aéreo que a globalização vai inserir o Município de Eirunepé no seu circuito econômico de produção. Neste contexto, "[...] o papel essencial do circuito inferior é o de permitir que as classes menos favorecidas tenham acesso, por formas específicas de comercialização, aos produtos fabricados no circuito superior [...]" (SANTOS, 2014, p. 92). No entanto, esses espaços opacos, com pouca tecnologia, são dependentes do circuito superior (SANTOS; SILVEIRA, 2001). 
A análise de um lugar na Amazônia nos permite entender cidades invisíveis como Eirunepé (SCHOR; OLIVEIRA, 2013), lugar onde a urbanização aflorou e modificou os modos de vida. "Apesar da quase inexistência de bibliografias sobre a cidade, a mesma tem um papel importante no imaginário amazônida, pois é referência para 'lugar distante', pois leva-se de 15 a 22 dias de balsa para chegar lá" (SCHOR; OLIVEIRA, 2013, p. 68). Nesse viés, a cidade de Eirunepé tem o rio Juruá como principal via de acesso a outros lugares da região. Além do transporte fluvial tradicional, atualmente a população residente no município utiliza o transporte aéreo para se deslocar a Manaus, a cidades vizinhas e ao Estado do Acre. Esse modo de transporte aéreo está sendo bastante usado pela população, pois de Manaus até Eirunepé o percurso leva aproximadamente 30 dias durante a vazante e em torno de 15 a 22 dias durante a cheia, em função das características físicas dos rios Juruá e Solimões/Amazonas. Por via aérea, são aproximadamente três horas de viagem, com conexão em Tefé.

Os modos de transportes e de comunicação permitem a organização mais coesa da rede urbana no Estado do Amazonas (RODRIGUES, 2018), assim como representam uma rearticulação no território (SANTOS; SILVEIRA, 2001). Isso significa que mesmo os centros urbanos estando distantes geograficamente podem estar próximos através dos meios de comunicação (telefone, internet, rádios etc.) e transporte (fluvial e aéreo). O transporte aéreo em Eirunepé permite o fluxo de mercadorias, dinheiro e pessoas, através de duas empresas aéreas que realizam viagens semanais.

A primeira é a MAP Linhas Aéreas que realiza dois voos semanais e utiliza aeronaves ATR-42 com capacidade para 70 passageiros; a segunda é a empresa Amazonaves que faz três voos por semana, utilizando aeronaves Grand Caravan com capacidade para até dois tripulantes e nove passageiros. Existem, ainda, empresas menores que realizam esta mobilidade na região, permitindo uma comunicação entre as cidades vizinhas, tanto no Estado do Acre como no do Amazonas. Podemos destacar também o papel da Força Aérea Brasileira, que esporadicamente apoia o município durante determinadas operações militares, disponibilizando vagas em suas aeronaves à população.

Vale destacar que os serviços das empresas aéreas limitam o acesso da maioria da população a este modo de transporte, uma vez que os preços das passagens são dispendiosos. Esta limitação promoveu a inquietude para a realização desta pesquisa, que teve como objetivo compreender o transporte fluvial e aéreo no município de Eirunepé Amazonas.

Diante disso, percebe-se a importância do transporte aéreo e fluvial para a integração da Região Amazônica com o restante do país, pois além de servir para o fluxo de mercadorias e pessoas, os modos de transporte, especificamente o aéreo, são utilizados para transportar pessoas com graves problemas de saúde, em função do município ter poucos especialistas e 
espaços inadequados para determinados atendimentos. Neste sentido, é comum as pessoas irem a Manaus em busca de especialistas.

Com base nos relatos dos entrevistados, existem pessoas que nunca saíram de Eirunepé para outros lugares, pois alegam que comprar uma passagem aérea comprometeria a renda familiar. Diante do exposto, considera-se que o transporte aéreo foi pensado e criado para atender uma determinada classe de pessoas. Em suma, "[...] o espaço foi produzido para possibilitar a expansão do capital [...]" (OLIVEIRA, 2000, p. 44) e não a reprodução da vida.

Esta pesquisa foi desenvolvida no campo da investigação, através de pesquisa de campo e baseada no método empírico, indutivo, qualitativo e quantitativo. A coleta de dados foi realizada por meio de entrevistas semiestruturadas, que teve um número de mil participantes. Os entrevistados foram: os comerciantes, os empresários, os servidores públicos, trabalhadores que recebem um salário mínimo (atividade formal ou informal) e beneficiários do Programa Bolsa Família. O objetivo foi entrevistar diferentes classes sociais e obter resultados diversos. Além disso, realizou-se visita no aeroporto de Eirunepé, coleta de dados secundários em sites da ANAC, conversa informal com a gerência do aeroporto, observou-se o fluxo de passageiro por porto e no aeroporto, e realizou-se visita à capitania dos portos.

\section{DESENVOLVIMENTO}

\section{Caracterização da Cidade de Eirunepé}

A cidade de Eirunepé localiza-se na Microrregião do Juruá e Mesorregião Sudoeste Amazonense, à margem direita do Rio Juruá, sendo uma área florestada de característica equatorial, densa e fechada, com uma altitude de 124 metros acima do nível do mar e clima Equatorial. Possui extensão territorial de aproximadamente 15.878 quilômetros quadrados, com uma distância de aproximadamente 3.448 quilômetros via fluvial e 1.160 quilômetros por via aérea em linha reta, em relação a Manaus. Faz limites com os municípios de Itamarati, Envira, Ipixuna, Benjamin Constant, Jutaí e Estado do Acre. Com população de 30.665 habitantes, conforme dados do IBGE, 2010 (Instituto Brasileiro de Geografia e Estatística), tem densidade demográfica de aproximadamente 2,04 hab./km².

Ao fazer uma comparação com a tipologia urbana das cidades da calha do Solimões, proposta estabelecida por Schor e Oliveira (2011), Eirunepé pode ser caracterizada como cidade pequena de responsabilidade territorial, que segundo Schor e Moraes (2008), exerce influência entre os fluxos de transportes e comercialização, entre as cidades médias e os demais núcleos urbanos. Esta influência é percebida pela intensidade de fluxos de pessoas e mercadorias, que se utilizam do meio de transporte aéreo entre as cidades da calha do Juruá, 
afluentes (Eirunepé, Envira, Ipixuna, Itamarati, Guajará) e Solimões (Tabatinga, Tefé, Carauari, Manaus).

De acordo com o IBGE, obedecendo às determinações do REGIC (Região de Influência das Cidades), Eirunepé é uma cidade, na hierarquia urbana, caracterizada como centro de zona $B$, exercendo uma influência sobre as cidades ao seu entorno, da região do Juruá (IBGE, 2008). A Figura 1 mostra a localização do município de Eirunepé no Estado do Amazonas.

Figura 1 - Localização do Município de Eirunepé-Amazonas

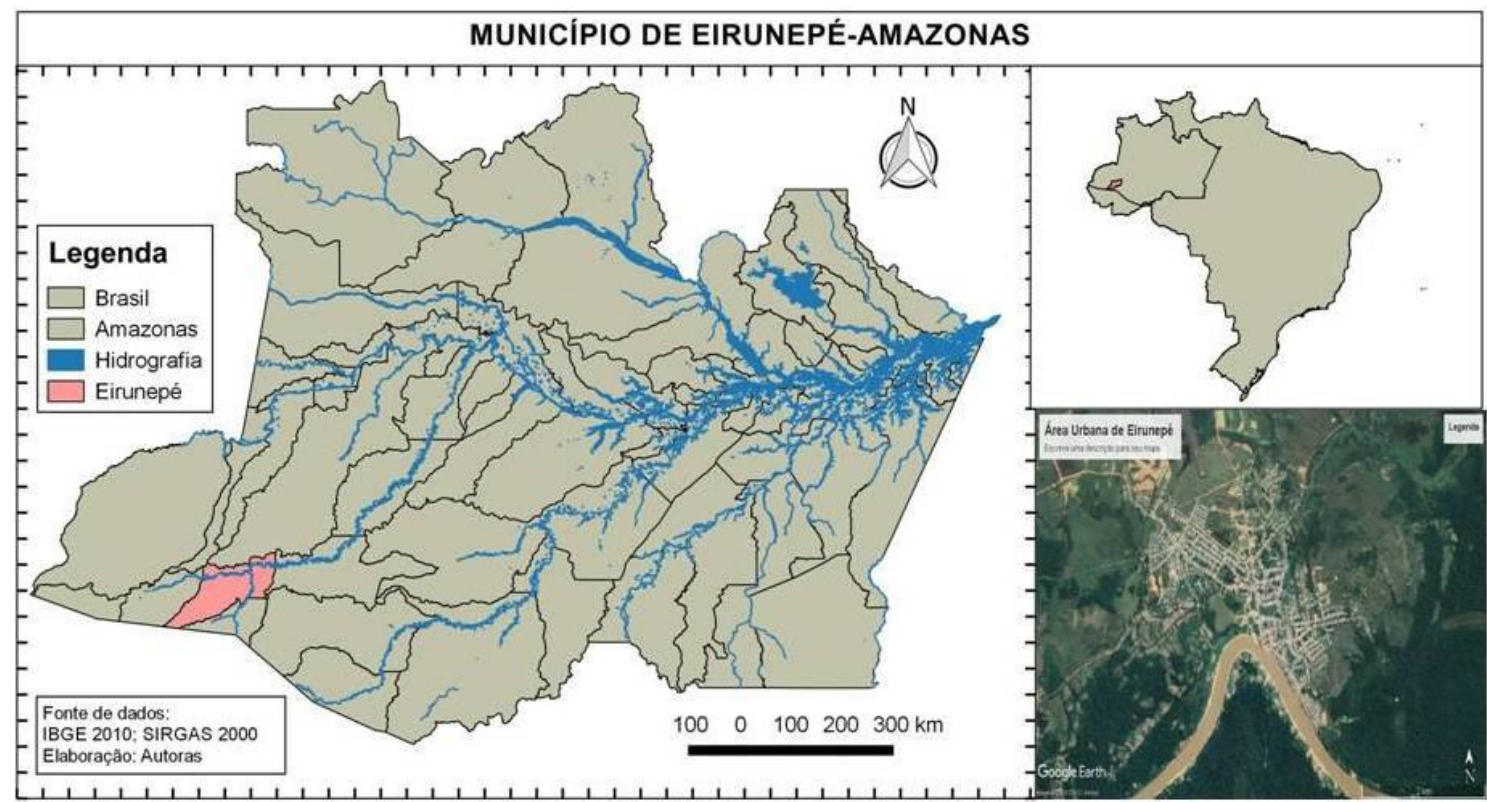

Fonte: IBGE (2010).

Segundo dados do IBGE (2010), a cidade de Eirunepé (área urbana) tinha 6.974 domicílios entre apartamentos, casas e cômodos. Desse quantitativo, 4.182 próprios, 4.182 próprios já quitados, 23 em aquisição, 148 alugados, 270 imóveis cedidos, sendo 125 por empregador, 145 cedidos de outra maneira, e 90 foram ocupados de outra forma. Esses domicílios têm serviços básicos como: água tratada, energia elétrica, limpeza urbana e rede de telecomunicações. Em relação aos serviços de saneamento básico, no ano de 2000, $52,15 \%$ dos domicílios tinham abastecimento de água; $71,99 \%$ possuíam coleta de lixo e $7,75 \%$ das residências tinham algum tipo de escoadouro sanitário (IBGE, 2000). 


\section{Geografias da Circulação: os Fluxos Fluviais e Aéreos na Amazônia}

A colonização e formação territorial das cidades na Amazônia foram palco de muitas conquistas e conflitos. Nesse contexto, diversos sujeitos contribuíram para o surgimento dos núcleos urbanos. Historicamente, as cidades não surgiram por acaso (ARAÚJO, 1998), e o processo de ocupação aconteceu por via fluvial, pois era a única maneira de acesso aos povoados na Amazônia.

Neste sentido, os rios são as nossas estradas (OLIVEIRA, 2000); e o rio comanda a vida na Amazônia (TOCANTINS, 2000). Conforme Oliveira (2000, p. 35), "[...] na Amazônia, chega-se à maioria das cidades pelo rio e delas é possível contemplar uma paisagem cujo limite é o reencontro das paralelas no horizonte em que o céu e as águas parecem se abraçar, quer se olhe em direção ao Ocidente ou Oriente".

O rio tem importância e significado para os amazônidas, sua dinâmica de subida e descida influencia nos modos de vida dos ribeirinhos. "A vazante deixa rios apenas com filetes de águas e as enchentes chegam a destruir residência" (SOUZA; ALMEIDA, 2010, p. 3). Esses impactos estão relacionados a questões climáticas, porém esses rios influenciam diretamente na dinâmica da cidade, na alimentação e no deslocamento. De acordo com Oliveira (2000, p. 36),

As cidades Amazônicas, pelo menos as localizadas às margens dos grandes rios, parecem ter sido criadas para serem vistas de longe, pois de perto toda a dimensão de beleza que existia no primeiro olhar esvai-se no arruamento caótico, nas casas novas, mas com as fachadas desbotadas e precocemente envelhecidas. Talvez fosse melhor que delas só tivéssemos a primeira impressão.

A primeira paisagem que se vê ao chegar fluvialmente na cidade de Eirunepé é de um barranco e as casas de palafitas. Considerando a distância, as características físicas do rio Juruá e a sua dinâmica, vale ressaltar que se torna inviável o transporte de pessoas durante a vazante, o que motiva o desinteresse por parte das empresas em oferecer esse tipo de serviço. Em pleno século XXI, não existe nenhum barco que oferece serviço de viagem para Manaus.

Dessa forma, compreender os fluxos entre Eirunepé e demais cidades do Amazonas consiste num grande desafio. Em uma região que conta com a ausência de estradas deve-se admitir que a mobilidade dos indivíduos tivesse possibilidade de se expandir por outros modos de transporte. A partir desse pressuposto, vale afirmar que a possibilidade de abertura de estradas seria quase impossível, devido às questões físicas e geográficas da região. Isso impulsionou a população à busca por alternativas que atendessem ao direito do ir e vir (OLIVEIRA NETO; NOGUEIRA, 2015). 
Diante de um contexto econômico e cultural internacional, a disputa entre os capitais é devastadora. Isso acontece pelas formas de reestruturação espacial em escala local, regional e global. O transporte moderno desempenha função importante para a ampliação do mercado mundial, em que espaço e tempo tomam variadas proporções, formas e condições se alteram, emergindo, assim, algumas particularidades dos processos sociais globais, em que o regional tende a moldar-se para atender a demanda global, como destaca Moreira (2008, p. 53):

De imediato, o aparecimento do motor elétrico aperfeiçoa o transporte ferroviário e marítimo. Por sua vez o motor a explosão, surgindo quase ao mesmo tempo, amplia o âmbito do alcance do transporte aéreo. O caminhão estabelece o transporte porta a porta, impossível de ser realizado pela ferrovia. O avião, por sua vez, encurta o tempo dos percursos e dá um novo sentido a distância física. E assim rodovia, ferrovia, navegação marítima e aerovia se integram em rede, com o transporte rodoviário cumprindo em nível terrestre o papel de ordenamento do arranjo antes cumprido pela ferrovia, e a aviação dividindo com a navegação marítima o papel internacional antes cumprido por esta.

Sob esta perspectiva, os serviços oferecidos na cidade de Eirunepé transferem ao lugar uma importante função, naturalmente destacados por superlativos e por uma seletiva valorização dos espaços. Observou-se, com o avanço tecnológico, o surgimento de novas formas, estruturas, processos e funções, isso facilitou o fluxo de mercadoria, pessoas e dinheiro no município de Eirunepé. Neste sentido, "Planejamento urbano, de transporte e de circulação, são na verdade instrumentos pelos quais se procura superar os conflitos existentes entre os diferentes atores que atuam na estruturação espacial da cidade" (SILVA, 2011, p. 5). O problema é que esse planejamento é realizado para o capital e não para a sociedade humana que vive.

As estratégias na comercialização de passagens e mercadorias levam ao entendimento a respeito dos diversos interesses oriundos dos atores públicos e privados. Vale aqui ressaltar o caso da Panair do Brasil, companhia aérea criada em 1930, a primeira empresa brasileira a voar regularmente para outros continentes. Foi desativada durante o regime militar, em 1965, em um processo de cassação, o qual está obscuro até hoje.

Esta análise articula-se com as diferentes escalas geográficas, elemento importante do método geográfico para compreender algumas características dos processos de comercialização de navegação aérea em regiões da Amazônia. Isso nos faz pensar também na reorganização da rede de transporte e nas modificações estruturais para atender ao novo tipo de demanda. Sendo assim, os modos de transportes, em especial a aviação, têm sofrido transformações, tanto institucionalmente, quanto no processo de produção de aeronaves. De acordo com Nogueira (2008, p. 44): 
A modernização dos meios de transportes em quase todas as modalidades permitiu uma substancial alteração nas referências no tempo e espaço. Ampliação da capacidade de passageiros e cargas e aumento da velocidade asseguram a expansão da mobilidade de pessoas e mercadorias.

A continuidade dos sistemas está vinculada às modernizações em que cada período representa uma compulsão voltada para a elaboração de formas e ações que possam atender às necessidades de um determinado lugar, essa organização do espaço pode ser apresentada como o resultado da harmonia entre os fatores de fragmentação e concentração, em um determinado momento da história do espaço.

\section{RESULTADOS E DISCUSSÃO}

No período técnico-científico-informacional, as formas de produção e reprodução espacial se alteram e intensificam-se a partir da necessidade de consumo, bem como a circulação de bens e pessoas. Dessa maneira, a partir dos serviços bancários, instituições educacionais (públicas e privadas) e serviços públicos, a cidade de Eirunepé passou a ter uma responsabilidade territorial, na Microrregião do Juruá.

O transporte aéreo constitui-se como principal serviço para chegar e sair do município de Eirunepé. Salienta-se a importância também no transporte de mercadorias, pois o transporte aéreo é mais rápido do que o transporte fluvial. Nas balsas, os preços das mercadorias transportadas variam de acordo com o tipo de produto, sendo cobrado de 8 a $10 \%$ sobre o valor da nota fiscal em produtos como eletrodomésticos e eletrônicos, e em torno de $R \$ 15,00$ a $R \$ 50,00$ reais no volume em outros tipos de mercadorias. Apesar da disponibilidade dessa modalidade de transporte e o preço mais barato, leva-se mais tempo, por isso os aviões são mais procurados para o transporte de pessoas e alguns tipos de mercadorias, além de serem mais rápidos e confortáveis.

Com base na classe de rendimentos nominal mensal domiciliar, do IBGE (2010), considera-se a população de Eirunepé de baixa renda, pois dos 6.974 somente 6.245 domicílios apresentam uma renda mensal, reduzindo para a escala urbana esse número diminui para 4.628 domicílios, o que de certa forma resulta em obstáculos para a aquisição dos serviços oferecidos pelo transporte aéreo, dificultando o acesso da população local a outros lugares como Manaus, Rio Branco (capital do Acre), em busca de tratamento médico, trabalho e estudos.

Com base nos relatos dos entrevistados, como alguns comerciários, percebe-se que existem também pessoas que nunca saíram de Eirunepé para outros lugares, pois alegam que para comprar uma passagem aérea teriam que abrir mão de uma significante quantia, uma vez que consideram o preço elevado, o que comprometeria a renda familiar. 
Diante do exposto, considera-se que existe um monopólio que se caracteriza cada vez mais pela forma de atuação das empresas. Estas apresentam, claramente, uma seletividade nos padrões de exigência para quem será essa produção e como será a circulação desses bens e serviços, pois os valores assumem diferentes significados, implicando em uma crescente desigualdade social, em que a capital dita as regras. Porém, ainda assim, percebese a relevância que este possui para diversos grupos e que mesmo diante da dificuldade financeira, em determinadas situações, como em casos de problemas de saúde, utilizar o serviço se torna necessário.

Nesse contexto, a falta de alternativas faz com que o transporte aéreo apresente grande relevância, tornando-se necessário e indispensável, pois além de transportar pessoas, transportam mercadorias que também abastecem a cidade, como é o caso da Agência dos Correios (é incomparável ao tempo gasto no modo fluvial).

Apesar do preço elevado desses serviços e em virtude da necessidade de bens de consumo e de mobilidade, o fluxo de mercadorias e a circulação de pessoas são constantes. Atualmente, existem cinco empresas que prestam esses serviços, mas apenas duas fazem o percurso Manaus/Eirunepé, as outras são taxis aéreos que fazem o trecho Eirunepé/Envira/Rio Branco e Eirunepé/Cruzeiro do Sul. Há ainda uma empresa, "Decolando com Você", que faz o trecho Eirunepé/Tabatinga uma vez por semana ou esporadicamente, fazendo voos somente quando atinge um determinado número de passageiros. A empresa alega que tem que completar o número de passageiros na ida e na volta, caso isso não aconteça implica prejuízo para ela.

A pouca frequência de inspeções da ANAC (Agência Nacional de Aviação Civil) ocasiona os tráfegos de voos ilegais na região, além disso, permite o funcionamento de voos em péssimas condições de tráfego. Desta forma, a atividade aérea pode ser exercida fora dos padrões estabelecidos. Neste segmento, a estrutura do aeródromo da cidade de Eirunepé não está de acordo com as normas estabelecidas pela ANAC. Durante a pesquisa de campo, verificou-se também a presença de bombeiros civis, os quais até pouco tempo não dispunham de Equipamentos de Proteção Individual (EPI), porém, através da parceria firmada entre o Comando da Aeronáutica e a Prefeitura Municipal de Eirunepé, em 2018, conseguiu-se solucionar o problema.

A dependência do aeroporto Amaury Feitosa Tomaz (Figura 2) ainda apresenta infraestrutura precária em relação aos critérios estabelecidos pela Infraero, que considera a estrutura física como: terminais de passageiros e cargas, pintura de pistas, pintura dos pátios. $\mathrm{Na}$ infraestrutura operacional: Instrument Lang System - ILS - Sistema Informativo de Uso (SIU), emergência médica e a estrutura administrativa. Esse aeroporto possui operações do tipo aviação comercial doméstica regular, aviação geral doméstica, e está localizado na 
cidade de Eirunepé, a cerca de cinco quilômetros do centro da cidade. A Prefeitura Municipal é responsável por sua operacionalização.

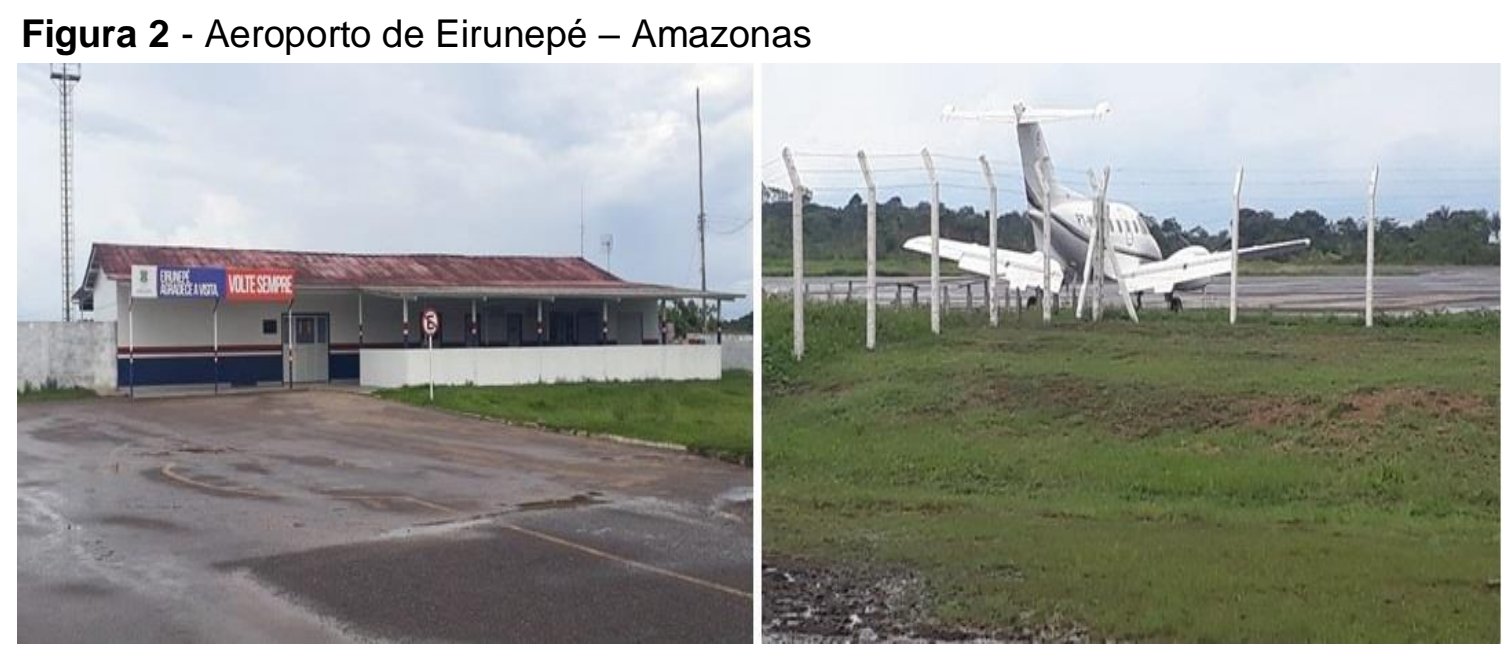

Fonte: Pesquisa de Campo, 2019.

Em virtude da necessidade de locomoção das pessoas até Manaus, percebeu-se que a maioria da população, mesmo sendo de baixa renda, utiliza o transporte aéreo, pelo fato de não existir outro modo de transporte de passageiros até Manaus. O tráfego torna-se mais intenso durante os meses de outubro a janeiro, pelo fato de ser o período de férias de final de ano, e muitos estudantes que moram em Manaus retornam para Eirunepé. A Figura 3 mostra a rota da aviação no município de Eirunepé-AM.

É possível perceber a relevância que esse transporte aéreo representa para a população e para o comércio da região. Nesse sentido, "[...] dentro da mesma aglomeração, cria-se um circuito de transporte privilegiado e o tempo social conhece uma nova escala, superpostas às já existentes" (SANTOS; SILVEIRA, 2001, p. 58). Nesse caso, as escalas se comprimem diante da globalização.

Por meio da empresa Amazonaves, com base administrativa em Manaus e base operacional na cidade de Tefé, realiza-se um voo por semana, transportando cerca de 1.200 quilos de carga, que são distribuídos em algumas cidades como Carauari, Tefé, Eirunepé, Envira, Tabatinga e São Paulo de Olivença. A Agência de Correios também utiliza o transporte fluvial que todos os meses transporta cerca de três toneladas e meia de cargas.

A empresa Amazonaves realiza o transporte de mercadorias, mas a prioridade está voltada para o transporte de passageiros. Quando a empresa iniciou atividade comercial em Eirunepé, no ano de 2015, a passagem custava $R \$ 700,00$ (setecentos reais), atualmente a passagem Manaus/Eirunepé custa $\mathrm{R} \$ 1.100,00$ (mil e cem reais), e Eirunepé/Manaus $\mathrm{R} \$$ 1.000 (mil reais). A empresa utiliza uma aeronave Grand Caravan modelo C 208e, que comporta nove passageiros, e dois tripulantes, transporta 600 quilos de carga e realiza o total 
de três voos por semana. Faz a rota Manaus, Carauari, Itamarati, Eirunepé e uma vez por semana faz o trecho Eirunepé/Envira. Os aviões são mais procurados pela falta de opção via fluvial e, também, por levar menos tempo.

Figura 3 - Rota da aviação no município de Eirunepé - Amazonas

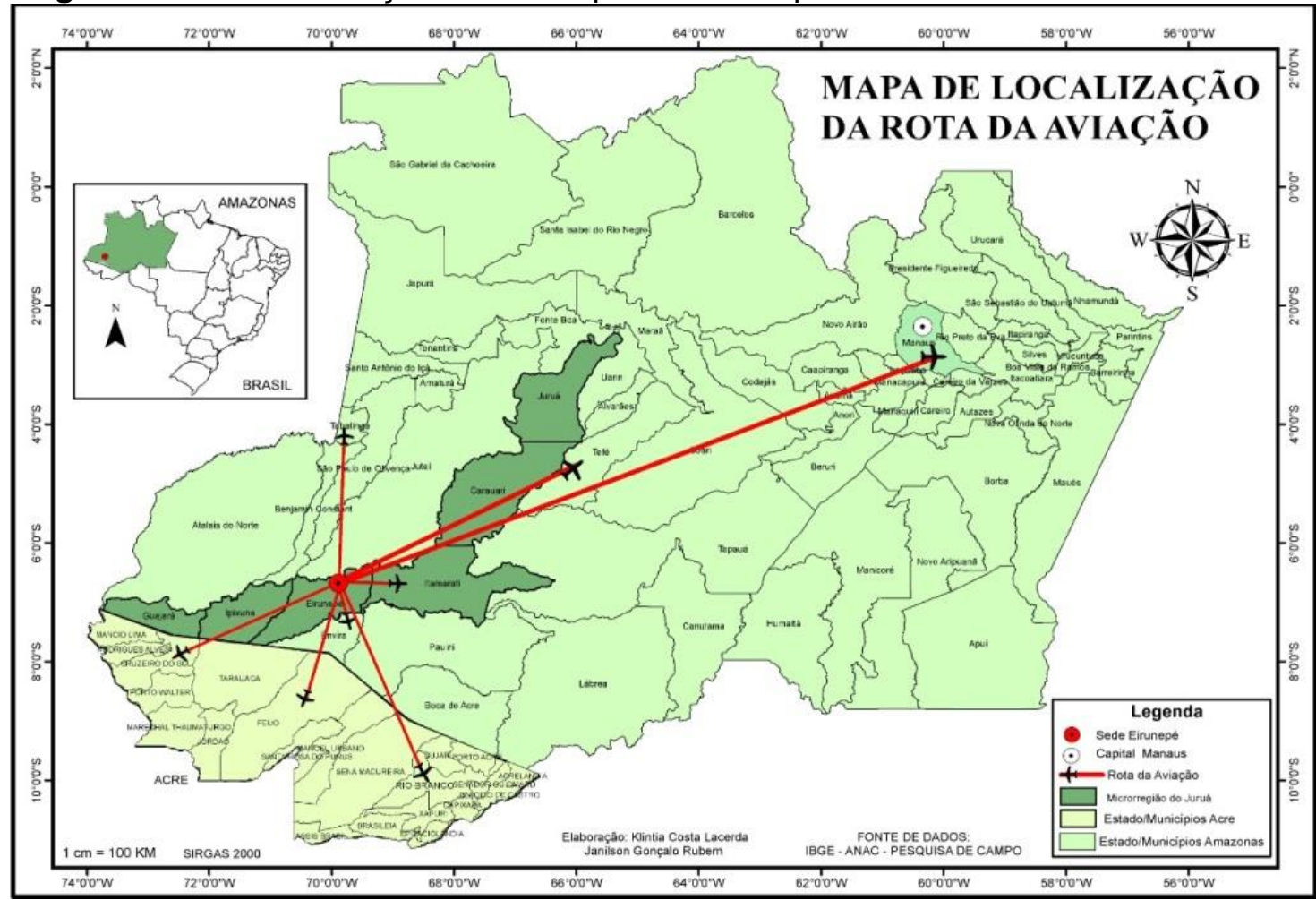

Fonte: Pesquisa de campo, 2019.

Em entrevista realizada com o administrador de quatro áreas da empresa MAP Linhas Aéreas, foi possível ter acesso a algumas informações. $O$ abastecimento das aeronaves é realizado na cidade de Tefé por motivo de não terem relações comerciais com a cidade de Tabatinga (apesar da proximidade com Eirunepé, existem empresas maiores na cidade como a Azul Linhas Aéreas). Ele declarou que o foco da empresa não era transportar passageiros vindo/indo para Tefé, porém em virtude do voo ter que parar na cidade a empresa transporta os passageiros de Tefé a Manaus, e vice-versa.

Para que uma aeronave de maior porte possa fazer o trajeto Manaus/Eirunepé, o aeroporto deveria ser certificado de acordo com as normas estabelecidas pela ANAC, como melhoria da infraestrutura da cidade, um hospital acima de 80 leitos, serviços de hotelaria e outros. A demanda mensal é de aproximadamente 4.500 passageiros. Alegou-se ainda que um dos fatores para que uma aeronave maior fizesse esse trajeto seria a demanda, e que esse número talvez não seja interessante para uma empresa de grande porte, além disso, a variação de preço também dependeria da disponibilidade de assentos. Os dados a seguir mostram por qual motivo as pessoas utilizam o transporte aéreo (Figura 4). 
Figura 4 - Dados das entrevistas realizadas entre outubro de 2018 a junho de 2019 na cidade de Eirunepé-AM

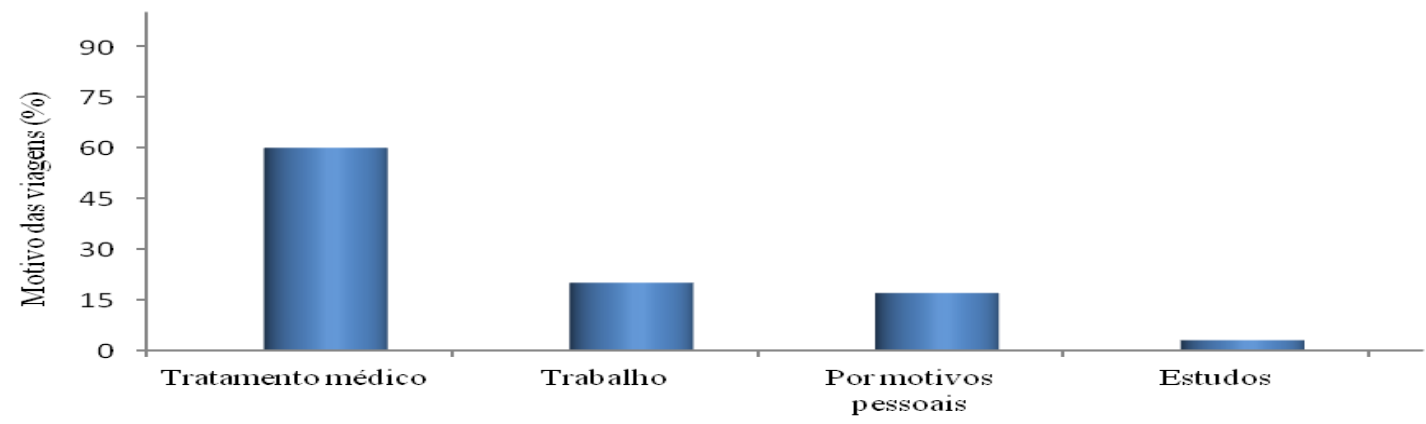

Fonte: Pesquisa de Campo, 2019.

A partir das respostas, temos os seguintes resultados: $60 \%$ dos entrevistados viajam para tratamento médico na capital (Manaus) e 5\% por motivo de estudos. O Quadro 1 também apresenta os motivos pelos quais as pessoas utilizam o transporte aéreo e o fluvial para o transporte de mercadorias.

Quadro 1 - Os motivos pelos quais os passageiros utilizam o transporte aéreo e fluvial

\begin{tabular}{|l|l|l|c|}
\hline \multicolumn{1}{|c|}{ Transporte Fluvial } & \multicolumn{2}{c|}{ Transporte Aéreo } \\
\hline \multicolumn{1}{|c|}{ Motivos } & $\%$ & \multicolumn{1}{c|}{ Motivos } & $\%$ \\
\hline Falta de alternativa & $45 \%$ & Falta de alternativa & $80 \%$ \\
\hline Por ser mais barato & $45 \%$ & Por ser mais rápido & $10 \%$ \\
\hline Capacidade de transporte & $10 \%$ & Mais seguro & $10 \%$ \\
\hline
\end{tabular}

Fonte: Entrevistas realizadas entre outubro de 2018 e junho de 2019.

Dos entrevistados, $45 \%$ afirmaram que utilizam o transporte fluvial para transportar suas mercadorias por ser mais barato. Se a mercadoria for produto eletrônico, eletrodomésticos ou móveis, eles pagam em média de 8 a 10\% do valor da nota fiscal, mas se for outro tipo de mercadoria eles pagam por volume que custa em torno de $R \$ 10,00$ a $R \$ 50,00$ reais, o que representa uma grande diferença se comparado ao valor do frete aéreo que é cobrado por peso.

Segundo o administrador, após a recente visita a Eirunepé a ANAC deu um parecer sobre a situação do aeroporto. O relatório apresenta os critérios que devem ser ajustados para que a certificação do aeroporto seja liberada como: pintura de pista, instalação de radar, construção da RESA (área de segurança de fim de pista), as cabeceiras da pista apresentam irregularidades topográficas, pois foi detectado que a cabeceira de ํㅡ 34 apresenta um aclive e a de no 16 apresenta um declive; a pavimentação do pátio operacional apresenta alguns rompimentos na estrutura; a área de sítio aeroportuário não possui cerca de delimitação, esta deve apresentar 2,10 metros de altura, ser construída em forma de mureta e alambrado para delimitar a área. 
Atualmente, o aeroporto não possui posto de abastecimento para querosene de aviação, razão pela qual a aeronave é obrigada a deixar 15 passageiros no trajeto Tefé/Eirunepé. É preciso despachar os passageiros devido à disponibilidade de peso para abastecer e para ter combustível suficiente para sobrevoar 30 minutos sobre Eirunepé em caso de emergência. Na impossibilidade de uma nova aterrissagem o avião volta para a cidade de Tefé.

O Terminal de Passageiros (TPS) não possui pórtico, raios-x e sala de tráfego aéreo. Existem balizamentos em toda extensão da pista e máquina de acionamento do balizamento, porém este equipamento encontra-se com problemas técnicos, conforme foi relatado pelo administrador. O TPS não possui cerca operacional; esta seria utilizada para delimitar a área operacional (pista de pouso), evitando a entrada de pessoas e animais. Esses cuidados evitam eventuais acidentes.

$O$ atual administrador do TPS informou que um equipamento de raios-x já foi liberado. O projeto de instalação está pronto, mas falta executar a obra para instalação do mesmo e treinar os profissionais que deverão atuar na área. Segundo o administrador, no pessoal que compõe o quadro de funcionários, um total de 14 servidores receberam treinamento para o exercício da função designada.

Um dos motivos apontados para o elevado preço das passagens seria a falta de concorrência, pois, em virtude da falta de infraestrutura, poucas empresas manifestam interesse em fazer voos comerciais nessa região. A rigor, a prioridade dos voos é voltada para atender passageiros, bem como o transporte de bagagem e não de cargas, o que implica um fator negativo, pois como a prioridade está voltada para o transporte de passageiros, ocasiona demora e até falta de algumas mercadorias na cidade, considerando que o transporte fluvial, as balsas, leva muito tempo para chegar. Para que pudessem transportar cargas em quantidade, seria necessária a utilização de uma aeronave de maior porte, o que poderia ocasionar a diminuição do custo do frete.

Os preços das passagens na Map Linhas aéreas variam em torno de $R \$ 800,00$ a $R \$$ $2.500,00$ (Tabela 1). O valor da encomenda custa em torno de $R \$ 15,00$ a $R \$ 30,00$ o quilo. Na empresa Amazonaves a passagem custa em torno de $R \$ 1.000,00$ a $R \$ 1.100,00$; a encomenda (simples) de $R \$ 10,00$ a $R \$ 15,00$. Se for um envelope, existe outra tarifa onde é cobrado $R \$ 30,00$ o quilo para encomenda normal (o tempo para chegar é maior); $R \$ 50,00$ o quilo para a modalidade expressa (o tempo para chegar é menor); $R \$ 70,00$ o quilo na modalidade VIP (funciona como se fosse SEDEX). 
Transporte Fluvial e Aéreo na Amazônia Legal: um estudo de caso no Município de Eirunepé...

Tabela 1 - Preços de passagens e frete de mercadorias

\begin{tabular}{l|l|l|l}
\hline Empresa & $\begin{array}{l}\text { Valor da passagem } \\
\mathbf{R} \$\end{array}$ & $\begin{array}{l}\text { Valor normal da } \\
\text { encomenda }\end{array}$ & $\begin{array}{l}\text { Sedex/ Intermunicipal } \\
\text { interestadual }\end{array}$ \\
\hline MAP & $\begin{array}{l}\mathrm{R} \$ 800,00 \quad \text { a } \\
2.500,00\end{array}$ & $\mathrm{R} \$ 15$ a 30,00 & \\
\hline Amazonave & $\begin{array}{l}\mathrm{R} \$ 1.000,00 \quad \text { a } \\
1.100,00\end{array}$ & $\mathrm{R} \$ 10$ a 15,00 & \\
\hline Amazonave & & $\mathrm{R} \$ 30,00$ normal & \\
\hline Amazonave & & $\mathrm{R} \$ 50,00$ expresso & \\
\hline Amazonave & & $\mathrm{R} \$ 70,00$ vip & \\
\hline $\begin{array}{l}\text { Decolando com } \\
\text { você }\end{array}$ & $\mathrm{R} \$ 200,00$ a 500,00 & & \\
\hline $\begin{array}{l}\text { Dugomes Táxi } \\
\text { aéreo }\end{array}$ & $\mathrm{R} \$ 200,00$ a 450,00 & & $\mathrm{R} \$ 18,00$ Intermunicipal \\
\hline Correios/AM & & & $\mathrm{R} \$ 24,00$ Interestadual \\
\hline Correios/AM & & &
\end{tabular}

Fonte: Pesquisa de campo, 2018 e 2019.

Na empresa táxi aéreo Decolando com Você as passagens custam de $R \$ 200,00$ a $R \$$ 500,00 . O primeiro preço equivale para municípios mais próximo como Envira; o segundo para os municípios de Tabatinga-AM, Tefé-AM, Rio Branco-AC e Cruzeiro do Sul- AC.

$\mathrm{Na}$ empresa Dugomes Taxi Aéreo as passagens custam a partir de $\mathrm{R} \$ 200,00$ para o município de Envira; $R$ \$ 350,00 para o município de Feijó-AC; e $R \$ 450,00$ para os municípios de Cruzeiro do Sul-AC, Itamarati-AM e Tabatinga-AM. Na agência dos correios, as entregas intermunicipais custam em média $R \$ 18,00$ o quilo e as encomendas interestaduais custam em torno de $\mathrm{R} \$ 24,00$.

É fato que o transporte aéreo tem a maior velocidade no que se refere aos fluxos, porém o fluvial é o responsável pela circulação de mercadorias de grande porte e maior volume. A Figura 5 apresenta a estrutura do porto fluvial da cidade de Eirunepé e sua mobilidade.

Figura 5 - Porto Fluvial da cidade de Eirunepé - Amazonas

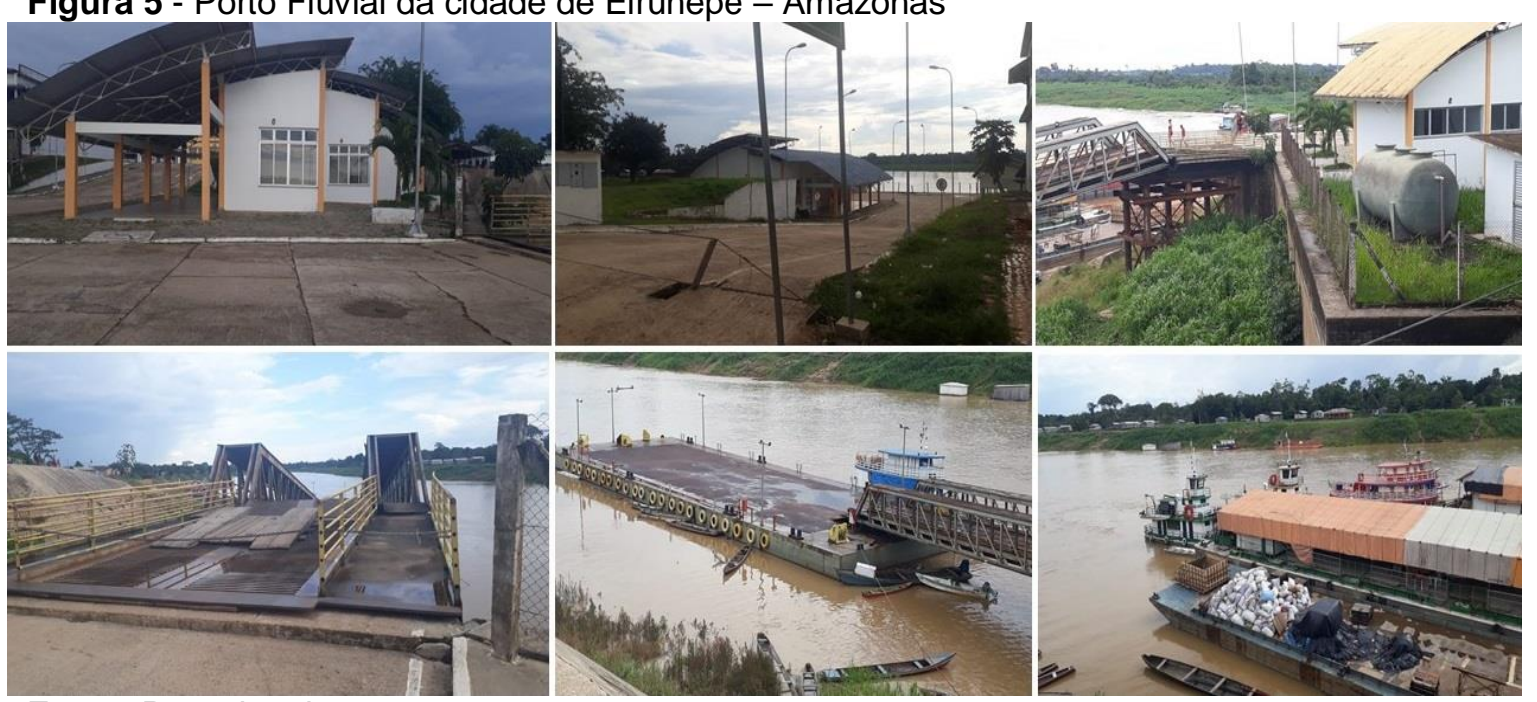

Fonte: Pesquisa de campo, 2019. 
Em março de 2012, o Departamento Nacional de Infraestrutura de Transportes (DNIT), órgão responsável pela construção do porto, liberou o funcionamento do Porto Fluvial de Eirunepé. O porto fluvial tem boa infraestrutura, tendo escritório administrativo, almoxarifado, instalações sanitárias, sala de atendimento ao público e estrutura especial para portadores de deficiência. Nesse processo de modernização, busca-se a fluidez da circulação e a redução de custos de operação (SANTOS; SILVEIRA, 2001).

Apesar da inexistência do transporte fluvial de passageiros, o porto fluvial trouxe melhorias tanto para a circulação de mercadorias como para os empresários, facilitando o embarque e desembarque.

Devido à falta de manutenção do porto de Eirunepé, alguns problemas técnicos foram surgindo, comprometendo as ponteiras de bases de ancoragem das balsas que funcionam como base de sustentação. Esse problema é decorrente do peso das embarcações que ancoravam no porto e da velocidade das águas. Segundo a administração, em função desta problemática a Capitania dos Portos, em novembro de 2017, interditou o mesmo, ficando proibida a ancoragem e permanência de qualquer balsa ou barco. Esta interdição implicou em sérios transtornos, pois para retirar as mercadorias necessita-se de uma grande mão de obra para carregar as mercadorias. Além disso, os transportes de carga terrestre não conseguem estacionar dentro da área do porto, dificultando o fluxo de desembarque e embarque feito pelos carregadores.

\section{CONSIDERAÇÕES FINAIS}

Esta pesquisa buscou compreender a dinâmica e os desafios dos fluxos aéreos e fluviais no município de Eirunepé - Amazonas. Ao analisar a dinâmica do transporte aéreo nesta cidade, observou-se que existem muitos entraves que afetam diretamente a mobilidade das pessoas, tanto no município quanto em cidades vizinhas, tornando o transporte aéreo uma necessidade básica para a população.

Constatou-se que a população eirunepeense em sua maioria depende desse tipo de transporte para locomover-se e ter acesso a outros lugares, principalmente à capital Manaus. O elevado preço representa uma problemática para boa parte desta população, principalmente para as pessoas de baixa renda, que muitas vezes precisam ir até a capital em busca de tratamento médico. Diante dessa condição social, o que se percebe é a grande dificuldade financeira que as pessoas apresentam para a aquisição desses serviços, tornando-se reféns, pois apenas uma classe de pessoas tem acesso a eles.

Tendo em vista a inexistência de transporte rodoviário e fluvial no âmbito do transporte de passageiros, a população é obrigada utilizar o transporte aéreo. Nesse sentido, o 
transporte aéreo desempenha relevante papel nesse segmento, pois contribui para o abastecimento do mercado local e dinamiza o fluxo de dinheiro.

Por estar localizado na Amazônia ocidental brasileira, o território de Eirunepé apresenta suas particularidades, tal como a distância. Há que se observar e reconhecer a dialética dos fluxos de pessoas, dinheiro e mercadorias, para a busca de melhorias dos serviços e preços.

Ao longo da pesquisa constatou-se a ausência de políticas públicas que viabilizem a melhoria dos transportes e mobilidade de pessoas e mercadorias. Com relação ao projeto para a construção do TPS, verificou-se que é uma obra ainda distante de acontecer e não tem prazo estabelecido para o início e conclusão. A busca de recursos é extremamente necessária e depende de ações participativas da prefeitura local. Esta é responsável por intermediar o processo junto aos órgãos competentes, pois é um recurso federal liberado pela SAC (Secretaria de Aviação Civil).

\section{REFERÊNCIAS}

ARAUJO, R. K. M. As cidades da Amazónia no século XVIII: Belém, Macapá e Mazagão. Porto: Faup Edições, 1998.

IBGE. Censo demográfico. 2000. Disponível em:

https://biblioteca.ibge.gov.br/visualizacao/periodicos/87/cd_2000_familias_domicilios_amostr a.pdf. Acesso em: 4 ago. 2019.

IBGE. Censo demográfico. 2010. Disponível em: https://censo2010.ibge.gov.br/. Acesso em: 4 ago. 2019.

IBGE. Regiões de influência das cidades - 2007. Rio de Janeiro: IBGE, 2008. Disponível em: https://www.mma.gov.br/estruturas/PZEE/_arquivos/regic_28.pdf. Acesso: 15 ago. 2019.

MOREIRA, R. Pensar e ser em geografia: ensaios de História, epistemologia e ontologia do espaço geográfico. São Paulo: Contexto, 2008.

NOGUEIRA, R. J. B. As redes geográficas na fronteira do Amazônia. Revista ACTA Geográfico, Boa Vista, ano 3, n. 3, p. 41-57, jan./jun. 2008.

OLIVEIRA NETO, T.; NOGUEIRA, R. J. B. Geopolítica e rodovias na Amazônia: um debate necessário. Revista de Geopolítica, Natal, v. 6, p. 166-186, 2015.

OLIVEIRA, J. A. Cidades na selva. Manaus: Valer, 2000.

RODRIGUES, E. A. Rede urbana do Amazonas: a dinâmica comercial no Médio Solimões a partir de Tefé. Revista Perspectiva Geográfica, Cascavel, v. 13, p. 92-105, 2018.

Disponível em: http://e-revista.unioeste.br/index.php/pgeografica/article/view/20765. Acesso: 22 set. 2019.

SANTOS, M. Economia espacial: críticas e alternativas. São Paulo: Universidade de São Paulo, 2014.

SANTOS, M.; SILVEIRA, M. L. O Brasil: território e sociedade no início do século XXI. São Paulo: Record, 2001.

SCHOR, T.; MORAES, A. O. O papel dos núcleos urbanos na manutenção da vida. In: CRUZ, G. V. P.; ANDRADE, S. (org.). Rio Negro, Manaus e as mudanças no clima. São Paulo: Instituto Socioambiental - ISA, 2008. v. 10, p. 47-52. 
SCHOR, T.; OLIVEIRA, J. A. As cidades invisíveis da Amazônia Brasileira. Mercator, Fortaleza, v. 12, p. 67-84, 2013.

SCHOR, T.; OLIVEIRA, J. A. Reflexões metodológicas sobre o estudo da rede urbana no Amazonas e perspectivas para a análise das cidades na Amazônia brasileira. Acta Geográfica, Boa Vista, v. 10, p. 15-30, 2011. Disponível em:

https://revista.ufrr.br/actageo/article/view/539. Acesso em: 19 ago. 2019.

SILVA, A. L. B. Circulação, transporte e espaço urbano. Revista de Geografia, Juiz de Fora, v. 2, p. 1-9, 2011.

SOUZA, J. C. R.; ALMEIDA, R. A. Vazante e enchente na Amazônia brasileira: impactos ambientais, sociais e econômicos. In: SEMINÁRIO LATINO AMERICANO DE GEOGRAFIA FÍSICA, 6., 2010, Coimbra, PT. Anais [...]. Coimbra: Universidade de Coimbra, 2010. p. 110.

TOCANTINS, L. O rio comanda a vida: uma interpretação da Amazônia. Manaus: Editora Valer, 2000. 